\title{
ÍNDICE DA SOLETRAS ATÉ O NÚMERO 22
}

\author{
José Pereira da Silva (UERJ) \\ pereira@filologia.org.br
}

\section{Introdução}

A partir deste número 22 da Soletras, nosso periódico passará a circular com o título Soletras Re-vista, com nova estrutura e com nova política editorial.

Até então dirigida pela Coordenação de Publicações sem uma participação significativa do conjunto dos docentes do Departamento de Letras, passará, agora, a ter uma assistência mais consistente da Chefia do Departamento, que passa a assumir efetivamente a sua função de Direção da revista.

Para facilitar e ampliar a consulta aos artigos e demais trabalhos publicados no periódico, organizamos um índice geral, com links para a publicação virtual, acreditando que isto ajudará na sua difusão.

\section{Breve história da revista}

SOLETRAS é a Revista do Departamento de Letras da Universidade do Estado do Rio de Janeiro, locado na Faculdade de Formação de Professores (Campus de São Gonçalo), nascida no segundo semestre do ano 2000, juntamente com a criação da Coordenação de Publicações e sua periodização é semestral, cujo primeiro número é do primeiro semestre de 2001, indexada como periódico semestral, com previsão para as edições ocorrerem até junho e até novembro todos os anos. Seu ISSN (International Standard Serial Number - Número Internacional Normalizado para Publicações Seriadas) é 1519-7778 e sua avaliação pelo Qua- 


\section{FACULDADE DE FORMAÇÃO DE PROFESSORES}

lis tem três avaliações: B4 em Educação e em Letras/Linguística e B5 em História na classificação realizada em fevereiro de 2010.

Seu Conselho Editorial teve, desde a origem, docentes do próprio departamento e professores externos, tendo sido renovado poucas vezes nesses onze anos de vida.

O Diretor da SOLETRAS é sempre o Chefe do Departamento de Letras ou alguém delegado por ele, mas é o editor que se responsabiliza pela coordenação dos trabalhos e pela sua editoração técnica (que pode ser o Coordenador de Publicações do Departamento ou quem for nomeado por ele), visto que a revista é o seu órgão oficial de comunicação acadêmico-científica.

Até este número, a SOLETRAS sempre saiu também como publicação virtual através da página http://www.filologia.org.br/soletras (apesar de nunca se haver registrado o ISSN da versão virtual) e integra o Almanaque CiFEFiL como publicação digital em CD-ROM, desde o primeiro número, cujo ISSN é 1676-3262. Através dessas versões em suportes digital e virtual, a revista tem boa circulação, porque a tiragem impressa é reduzidíssima.

Nesses onze anos, somente no terceiro foi realizada uma edição reunindo os dois números ( 5 e 6 ), quando o seu editor se afastou para gozar suas licenças-prêmio vencidas. Em compensação, nos outros dez anos, sempre teve as duas edições regulares, além de sete números suplementares, aproximando-se de quatro centenas de artigos.

\section{3. Índice}

Por limitação de espaço na versão impressa, será disponibilizada apenas a indexação por títulos dos artigos, visto que, apesar de reduzida sua formatação, ocupará mais de vinte páginas.

Aproveitamos para informar que todos esses artigos estão disponibilizados virtualmente e que os títulos aqui relacionados estão lincados com a respectiva edição virtual, em http://www.filologia.org.br/soletras

3.1. $2^{\mathrm{a}}$ fase do modernismo cearense: estudo linguístico-literário da obra Poesias Incompletas, de Antônio Girão Barroso

Kilpatrick Campelo (Ano 7 (2007), No 14, p. 09-26) 


\section{DEPARTAMENTO DE LETRAS}

3.2. A antiguidade clássica na obra de Ricardo Reis: da recensio à proposta de edição comentada

Jorge Henrique Nunes Pinto (Ano 10 (2010), No 19 - Suplemento, p. 09-18)

3.3. A argumentação no texto literário

Lilian Manes de Oliveira (Ano 7 (2007), No 14, p. 27-40)

3.4. À barca camoniana que farei com este livro?, Saramago

Regina Michelli (Ano 2 (2002), No 04, p. 07-21)

3.5. A cena aberta: multiplicidade polifônica nas narrativas de Sérgio Sant'Anna e João Gilberto Noll

Maria Isaura Rodrigues Pinto (Ano 4 (2004), № 07, p. 09-17)

3.6. À cata de um barrete: literatura, caricatura e imprensa no Brasil de 1890 - Leonardo Mendes e Nathalia Gorni (Ano 11 (2011), No 22, p. 09-18)

3.7. A ciranda do tempo na Lavoura Arcaica, de Raduan Nassar Regina Céli Alves da Silva (UniverCidade) (Ano 11 (2011), Nº 22, p. 19-26)

3.8. A circunfixação como processo de formação de palavras Patrícia Ribeiro Corado (Ano 2 (2002), No 04, p. 22-27)

3.9. A concordância verbal na gramática de usos do português (Maria Helena de Moura Neves, Editora Unesp, 2000) Angela Rodrigues e Elias Alves de Andrade (Ano 7 (2007), No 13, p. 07-14)

3.10. A contentio do livro I da Utopia de Morus Ricardo Hiroyuki Shibata (Ano 4 (2004), № 08, p. 09-27)

3.11. A crônica em sala de aula: trabalhando com um gênero menormenormenormenor... Maria Cristina Cardoso Ribas e Milena Salles Marques Domás e Ketiley da Silva Pessanha (Ano 9 (2009), No 18, p. 07-23)

3.12. A distribuição dos substantivos em gênero: uma proposta didática José Mario Botelho (Ano 10 (2010), № 20, p. 07-17)

3.13. A edição de textos não literários: o projeto documentos linguísticos do país basco, de Aara Fómez Aeibane (tradução) Aline Ribeiro de Freitas (Ano 10 (2010), No 19 - Suplemento, p. 19-32)

3.14. A edição moderna de textos do "siglo de oro": o caso de el pastor de filida, de Cristina Castillo Martínez (tradução)

Priscilla Lessa Machado (Ano 10 (2010), № 19 - Suplemento, p. 33-44)

3.15. A educação a distância e a realidade brasileira: paradoxos e dificuldades de comunicação e como a linguística aplicada pode analisá-los e apontar soluções Marcelo Moraes Caetano (Ano 9 (2009), N 18, p. 24-48)

3.16. A educação infantil e a construção de identidades sociais Renata Lopes de Almeida Rodrigues (Ano 8 (2008), No 16 - Suplemento, p. 148-163)

3.17. A educação romana e o destino do latim peninsular Afrânio da Silva Garcia (Ano 11 (2011), No 21, p. 07-21) 


\section{FACULDADE DE FORMAÇÃO DE PROFESSORES}

3.18. A elegia ovidiana

Márcia Regina de Faria da Silva (Ano 9 (2009), № 17- Suplemento, p. 09-14)

3.19. A epêntese do fonema " $i$ " nas flexões verbais

Ruy Magalhães de Araujo (Ano 1 (2001), No 02, p. 07-10)

3.20. A Escrava Isaura e a inviabilidade econômica da escravidão: considerações sobre o antiescravismo de Bernardo Guimarães

Kleberson da Silva Alves (Ano 9 (2009), № 17 - Suplemento, p. 15-24)

3.21. A escrita de histórias de literatura e a questão da realidade

Marcello de Oliveira Pinto (Ano 5 (2005), $\mathrm{N}^{\circ}$ 09, p. 07-18)

3.22. A escrita pseudoetimológica em Domingos Caldas Barbosa: carta a Pedro Rademaker $(1780)$

Fabiana Miraz de Freitas Grecco (Ano 9 (2009), № 17 - Suplemento, p. 25-38)

3.23. A estilística lexical e sintática aplicada a poemas

Gisele Palmieri(Ano 6 (2006), No 11, p. 07-13)

3.24. A estrutura composicional nos gêneros textuais a escrever: estudo de caso

Sílvio Ribeiro da Silva, Bárbara Battistelli Rauber e Lanilda Teles(Ano 6 (2006), No 11, p. 14-23)

3.25. A ética diminuta contra os escribas da amargura, do ressentimento e da melancolia: Julio Cortazar e Cacaso Iza Quelhas (Ano 9 (2009), № 18, p. 49-55)

3.26. A Eva e a Alma - Maria Paula Lamas (Ano 5 (2005), No 09, p. 19-26)

3.27. A evolução da edição gráfica

Fabiana Glória Costa Nunes (Ano 10 (2010), № 19 - Suplemento, p. 45-54)

3.28. A evolução do suporte material, do livro ao e-book: mudanças e impactos ao leitor contemporâneo

Roberta Kerr dos Santos (Ano 10 (2010), No 20, p. 18-30)

3.29. A expressão da futuridade nos manuais de ensino de português para estrangeiros Elisabeth Penzlien Tafner (Ano 5 (2005), № 09, p. 27-38)

3.30. A fábula A Raposa e o Bode (Esopo): uma abordagem semiótica Miguél Eugenio Almeida (Ano 8 (2008), No 15, p. 11-17)

3.31. A facilitação do ensino de morfologia na escola: o trabalho com textos Alexandre Delpech (Ano 8 (2008), N N $^{\circ}$, p. 18-25)

3.32. A Faculdade Paulista de Letras e Filosofia $\left(1^{\circ}\right.$ de junho de 1931$)$ Eduardo Tuffani(Ano 11 (2011), № 21, p. 22-29)

3.33. A flexão de gênero dos substantivos Antônio Sérgio Cavalcante da Cunha (Ano 8 (2008), No 15, p. 26-34)

3.34. A forma de organização informacional do discurso: uma proposta de análise para o estudo do tópico

Gustavo Ximenes Cunha (Ano 8 (2008), No 15, p. 35-44) 


\section{DEPARTAMENTO DE LETRAS}

3.35. A formação da leitura no Brasil

Leonardo Barros Medeiros (Ano 9 (2009), № 17-Suplemento, p. 183-187)

3.36. A guerra dos métodos na alfabetização

Vicente Martins (UVA) (Ano 8 (2008), No 15- Suplemento, p. 7-14)

3.37. A Ilustre Casa de Ramires: análise de variantes

Ânderson Rodrigues Marins (Ano 10 (2010), Nº 19 - Suplemento, p. 55-70)

3.38. A importância do processo neológico na construção de sentido de "O Bem-Amado", de Dias Gomes

Gabriela Farley M. Zambi (Ano 10 (2010), № 20 - Suplemento, p. 08-17)

3.39. A inclusão cultural letrada no século XIX: o papel da imprensa

Valéria Severina Gomes e Mari Noeli Kiehl Iapechino (Ano 8 (2008), № 15, p. 45 -

59)

3.40. A infầncia do visconde de Taunay no tempo do império: "acaso os heróis são feitos para serem tímidos?"

Iza Quelhas (Ano 1 (2001), № 01, p. 13-26)

3.41. A influência do perfil de leitor nas habilidades ortográficas

Jaime Luiz Zorzi; Marisa T. Serapompa; Adriana T. Faria; Polyana S. Oliveira

(Ano 8 (2008), No 15- Suplemento, p. 15-30)

3.42. A influência espanhola na edição de 1584 d'Os Lusíadas Maria Paula Lamas (Ano 6 (2006), Nº 11, p. 24-32)

3.43. A interdependência entre poesia, mito e ecologia: a obra poética como denúncia das práticas antiecológicas

Ivone da Silva Rebello e Eliana da Cunha Lopes (Ano 9 (2009), № 18, p. 56-73)

3.44. A interface ecoturística: uma análise discursiva

Angélica Alves Ruchkys (Ano 8 (2008), N 15, p. 60-74)

3.45. A língua portuguesa da África lusófona: uma proposta de ensino através da literatura Janice Cravo Piccoli (Ano 1 (2001), N N $^{\circ}$, p. 73-79)

3.46. A língua, a leitura e a escrita como um elo integrador Carmen Elena das Chagas (Ano 7 (2007), No 14, p. 41-46)

3.47. A literatura do século XIX e seus desdobramentos no ensino de língua portuguesa na atualidade com vistas ao preconceito linguístico

Livia Marinho Lessa Barboza (Ano 11 (2011), №22, p. 27-41)

3.48. A literatura e a estética literária na era da "indústria cultural": uma leitura de Budapeste, de Chico Buarque

Ilma da Silva Rebello (Ano 6 (2006), № 12, p. 07-19)

3.49. A malandragem como emblema nacional Leandro Nascimento Cristino(Ano 9 (2009), No 17- Suplemento, p. 39-51)

3.50. A marca do desejo em Cornélio Penna e Lúcio Cardoso Leandro Nascimento Cristino (Ano 9 (2009), No 17, p. 09-15) 


\section{FACULDADE DE FORMAÇÃO DE PROFESSORES}

3.51. A metáfora como leitura na obra de Bartolomeu Campos Queirós Maria Lilia Simões de Oliveira (Ano 1 (2001), № 01, p. 80-88)

3.52. A morte como protagonista Edina Regina P. Panichi (Ano 7 (2007), No 14, p. 47-55)

3.53. A nasalidade das vogais em português José Mario Botelho (Ano 7 (2007), No 14 , p. 56-64)

3.54. A nova ortografia Clarissa Josgrilberg Pereira entrevista José Pereira da Silva (Ano 9 (2009), № 17 Suplemento, p. 188-193)

3.55. A ordem dos clíticos em léxias verbais simples: uma análise das gramáticas tradicionais Cristiane Jardim Fonseca (Ano 8 (2008), Nº 15, p. 75-83)

3.56. A paráfrase em aulas para os ensinos médio e superior Paulo de Tarso Galembeck e Márcia Reiko Takao (Ano 1 (2001), No 01, p. 89-97)

3.57. A paráfrase no comentário jornalístico: uma estratégia discursiva Suzana Paulino P. D. de Carvalho (Ano 8 (2008), Nº 15, p. 84-89)

3.58. A poesia brasileira do fim do século XIX e da belle époque: parnasianismo, decadentismo e simbolismo Fernando Monteiro de Barros Jr. (Ano 9 (2009), № 17, p. 16-27)

3.59. A poética caracterizacão do elemento feminino em "Sinhá Secada": uma análise esti$\underline{\text { lístico-estrutural }}$ Maria Isaura Rodrigues Pinto (Ano 5 (2005), № 09, p. 39-49)

3.60. A poética de Lúcio Cardoso: o catolicismo da transgressão Fernando Monteiro de Barros (Ano 4 (2004), Nº 08, p. 28-48)

3.61. A poética dos Beatles Afrânio da Silva Garcia (Ano 2 (2002), No 03, p. 31-43)

3.62. A polêmica questão da categoria gramatical de gênero José Pereira da Silva (Ano 4 (2004), Nº 08, p. 49-68)

3.63. A posição de 'lá' na projeção nominal: contribuições para o mapeamento da estrutura funcional

Bruna Karla Pereira(Ano 9 (2009), № 17- Suplemento, p. 52-63)

3.64. A pressuposição na instância da avaliação escolar Ecyr Affonso de Souza (Ano 4 (2004), Nº 08, p. 69-83)

3.65. A questão da professora de amor em Amar, Verbo Intransitivo - Idílio de Mário de Andrade Dante Gatto (Ano 2 (2002), N 03 , p. 44-54)

3.66. A questão do poder em Auto da Feira Livia Fernanda Monteiro Sousa (Ano 7 (2007), No 14, p. 65-69)

3.67. A rara confluência do esquecido parnasianismo Luiz Fernando Dias Pita (Ano 2 (2002), Nº4, p. 87-100) 


\section{DEPARTAMENTO DE LETRAS}

3.68. A razão e a loucura: análise semiótica e antropológica do conto O Alienista de Machado de Assis

Karylleila dos Santos Andrade (Ano 10 (2010), No 20 - Suplemento, p. 185-190)

3.69. A relação denotação-conotação: uma questão de plurissignificação imanente

José Mario Botelho (Ano 6 (2006), № 12, p. 38-52)

3.70. A república manca: miragem, de Coelho Neto e o naturalismo da desilusão Leonardo Mendes e Renata Ferreira Vieira (Ano 9 (2009), No 18, p. 74-82)

3.71. A rubra escrita do corpo São Bernardo, de Graciliano Ramos Iza Quelhas (Ano 1 (2001), N 02, p. 93-106)

3.72. A situação oficial brasileira do filólogo e do professor de filologia no Ministério do Trabalho e Emprego

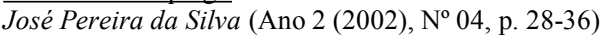

3.73. A teoria behaviorista da aquisição da linguagem

Vicente Martins (Ano 8 (2008), No 15- Suplemento, p. 31-34)

3.74. A tradição da crítica libertária e as concepções ideológicas hegemônicas Silvia Miranda Boaventura (Ano 1 (2001), No 01, p. 07-12)

3.75. A tradição discursiva: epitáfio em lápides tumulares do século XIX Fabiola de Jesus Soares Santana (Ano 8 (2008), No 15, p. 90-100)

3.76. A trajetória dos d'ávila no Brasil através dos livros de tombo do Mosteiro de São Bento da Bahia: proposta de mapeamento de documentos e edicãa fac-similarsemidiplomática-crítico-digital Jaqueline Carvalho Martins de Oliveira e Alícia Duhá Lose (Ano 10 (2010), № 19 Suplemento, p. 71-80)

3.77. A transitividade segundo a tradição gramatical e o funcionalismo Alex Swander e Karla Franco dos Santos (Ano 4 (2004), No 07, p. 18-28)

3.78. A variação linguística na sala de aula Renata Helena dos Santos (Ano 7 (2007), No 14, p. 70-85)

3.79. A verdade mítica e a fala poética em Ubirajara, de José de Alencar Alexandra Vieira de Almeida(Ano 6 (2006), No 11, p. 33-41)

3.80. A verdadeira arte de pensar a Literatura Priscila Guedes Buares (Ano 4 (2004), No 07, p. 29-33)

3.81. A visão de Matoso Câmara sobre a filologia José Pereira da Silva (Ano 4 (2004), Nº7, p. 34-45)

3.82. A visão sintática de Júlio Ribeiro Ânderson Rodrigues Marins (Ano 11 (2011), No 21, p. 30-38)

3.83. A voz africana na cultura brasileira e as culturas inversas entre Brasil e África João Carlos Gomes (Ano 10 (2010), N 19, p. 07-20)

3.84. A voz masculina no conto "Apelo" de Dalton Trevisan Elizangela Maria dos Anjos (Ano 5 (2005), $\mathrm{N}^{\circ}$ 09, p. 50-59) 


\section{FACULDADE de FormaÇÃo de PROFESSORES}

3.85. Absurdo e linguagem em A Náusea

Reinério Luiz Moreira Simões (Ano 6 (2006), No 12, p. 53-63)

3.86. Acerca da dinamicidade lexical

Vito Cesar de Oliveira Manzolillo (Ano 1 (2001), No 02, p. 11-19)

3.87. Acre, Juruá e Purus: áreas dialetais do Atlas Etnolinguístico do Acre

Luísa Galvão Lessa (Ano 11 (2011), N²2, p. 42-61)

3.88. Adaptação ou adulteração? Notas sobre o romance Mar Morto

Rosane Marins de Menezes (Ano 1 (2001), No 02, p. 107-111)

3.89. Adoniran Barbosa, o defensor involuntário do combate ao preconceito linguístico

Mônica Guedes Jogas e Nataniel dos Santos Gomes (Ano 3 (2003), Nº5-06, p. 22-

30)

3.90. Advérbios, uma abordagem crítica

Fernanda Cristina Saraiva (Ano 8 (2008), No 15, p. 101-106)

3.91. Aguarelas de Cesário Verde

Maria Paula Palmas (Ano 5 (2005), No 10, p. 07-15)

3.92. Algumas contribuições de Bakhtin, Schneuwly e Adam para os estudos sobre gêne$\underline{\operatorname{ros}}$

Sebastião Carlúcio Alves Filho e Silvio Ribeiro da Silva (Ano 10 (2010), № 20 - Suplemento, p. 18-29)

3.93. Algumas propostas de análise da coordenacão e da subordinacão a partir do comportamento das conjunções da área da causa e da explicação

Antônio Sérgio Cavalcante da Cunha (Ano 8 (2008), $\mathrm{N}^{\mathrm{o}}$ 16, p. 09-22)

3.94. Algumas reflexões sobre alfabetização e analfabetismo

Jacqueline de Fátima dos Santos Morais (Ano 9 (2009), No 17, p. 28-34)

3.95. Alguns aspectos da heterogeneidade dialetal brasileira: construções a partir dos pronomes sujeito e objeto

Vicente Cerqueira e Marcelo Leal Lima (Ano 10 (2010), № 20 - Suplemento, p. 191-196)

3.96. Amor e morte no romance de José Saramago

Maria de Lourdes Soares (Ano 7 (2007), No 14, p. 86-94)

3.97. Anáfora: da abordagem clássica à abordagem discursiva

Rachel Maria Campos Menezes de Moraes (Ano 11 (2011), № 21, p. 39-49)

3.98. Anáforas nominais: um processo de referenciação n' Orto do Esposo (fins do século XIV e começo do XV)

Maria Regina Pante e Adelli Bortolon Bazza (Ano 8 (2008), № 15, p. 107-118)

3.99. Análise de elementos estruturais linguísticos e literários de Aves de Arribação, de Antônio Sale

Kilpatrick Campelo (Ano 8 (2008), No 15, p. 119-132)

3.100. Análise de um poema da moderna literatura angolana

Leodegário A. de Azevedo Filho (Ano 2 (2002), No 04, p. 37-46) 


\section{Departamento de LetRAS}

3.101. Análise estilística do texto "Gigolô das Palavras", de Luís Fernando Veríssimo Janaína Oliveira, Patrícia Graeff Viana e Priscilla de Souza Cruz (Ano 7 (2007), N ${ }^{\circ}$ 14, p. 95-99)

3.102. Apólogo das cotovias: visão semiótica baseada na teoria de a. J. Greimas Miguel Eugênio Almeida (Ano 5 (2005), N 09, p. 60-66)

3.103. Aprender inglês para não perder o bonde da história Maria Cristina Damianovic (Ano 6 (2006), No 12, p. 20-31)

3.104. Aquisição de segunda língua de uma perspectiva linguística a uma perspectiva social Isabel Cristina Rangel Moraes Bezerra (Ano 3 (2003), No 05-06, p. 31-52)

3.105. As classes populares e as duras cavalgadas da vida: uma leitura de Vidas Secas, de Graciliano Ramos Ilma da Silva Rebello (Ano 5 (2005), Nº 10, p. 85-96)

3.106. As comparações do Barão Mary Neiva Surdi da Luz (Ano 7 (2007), № 14, p. 100-109)

3.107. As conjunções sob um prisma funcional Charleston Chaves (Ano 5 (2005), $\mathrm{N}^{\mathrm{o}}$ 10, p. 16-27)

3.108. As contribuições das teses inatistas para os estudos de aquisição e desenvolvimento da linguagem Rafael Lira Gomes Bastos (Ano 8 (2008), № 15- Suplemento, p. 35-41)

3.109. As diferentes realizações do s implosivo e da vibrante: reflexos de fatores histórico, sociais e demográficos da cidade do Rio de Janeiro Angela Marina Bravin dos Santos (Ano 7 (2007), No 13, p. 15-25)

3.110. As fases do desenvolvimento da linguagem escrita Janieri de Sousa Oliveira; Maria de Lourdes da Rocha; Conceição Elane; Maria Neuma Freire Araújo (Ano 8 (2008), № 15- Suplemento, p. 42-46)

3.111. As ferramentas para compreensão de um texto Charleston Chaves(Ano 7 (2007), No 14, p. 110-120)

3.112. As hipóteses do inatismo para explicação da linguagem Márcia Rejane Alves Rodrigues; Maria Neuma Freire Araújo (Ano 8 (2008), No 15 Suplemento, p. 47-50

3.113. As inversões de letras na escrita o "fantasma" do espelhamento Jaime Luiz Zorzi (Ano 8 (2008), № 15- Suplemento, p. 51-62)

3.114. As multifaces d'Os Sertões, de Euclides da Cunha Ruy Magalhães de Araujo (Ano 4 (2004), No 08, p. 84-95)

3.115. As personagens femininas e a ironia de Eça de Queirós Suely do Espírito Santo (Ano 1 (2001), Nº 01, p. 27-33)

3.116. As quatro adaptações recentes de O Alienista, de Machado de Assis em quadrinhos Bárbara Cristina Almada da Silva e Nataniel dos Santos Gomes (Ano 11 (2011), N ${ }^{\circ}$ 22, p. 62-82) 


\section{FACULDADE DE FORMAÇÃO DE PROFESSORES}

3.117. As relações entre cognição e afetividade em LA: a influência de Vygotsky nessa abordagem temática

Elisabeth Ramos da Silva (Ano 8 (2008), No 15, p. 133-140)

3.118. As trocas surdas sonoras no contexto das alterações ortográficas Jaime Luiz Zorzi (Ano 8 (2008), $\mathrm{N}^{\mathrm{o}}$ 15- Suplemento, p. 63-8-0

3.119. Aspectos linguísticos das dificuldades específicas em leitura Kétilla Maria Vasconcelos Prado; Lady Dayana de Lima e Silva; Maria do Nazaré de Carvalho; Teresinha Rodrigues Alcântara (Ano 8 (2008), No 15- Suplemento, p. 81-87

3.120. Até ao fim do mundo D'este viver aqui neste papel descripto de António Lobo Antunes

Maria de Lourdes Soares(Ano 6 (2006), No 11, p. 42-47)

3.121. Atribuiç̃ões do filólogo

Cristina Brito (Ano 5 (2005), $N^{o}$ 09, p. 67-71)

3.122. Auto: comunhão do sagrado e profano

Rosângela Divina Santos Moraes da Silva (Ano 9 (2009), No 17, p. 35-41)

3.123. Baudelaire, Byron e Lúcio Cardoso: a flânerie e o dandismo do vampiro Fernando Monteiro de Barros (Ano 3 (2003), No 05-06, p. 53-64)

3.124. Bibliografia Crítica de Gregório de Mattos e Guerra (Atualizada) Ruy Magalhães de Araujo (Ano 4 (2004), No 07, p. 46-58)

3.125. Bovinocultura e literatura Raquel Naveira (Ano 8 (2008), № 15, p. 141-147)

3.126. Breve estudo da argumentação em Se Se Morre de Amor, de Gonçalves Dias Marcia de Oliveira Gomes(Ano 8 (2008), No 15, p. 148-159)

3.127. Breves comentários sobre a obra $O$ Africano, de Jean-Marie Gustave le Clezio Antonio Carlos Lopes Petean (Ano 11 (2011), No 22, p. 83-88)

3.128. Caminhos da paixão e do amor na literatura portuguesa Regina Michelli (Ano 4 (2004), $\mathrm{N}^{\circ}$ 08, p. 96-105)

3.129. Campo lexical e neologia: criatividade linguística em favor da argumentação Anderson de Souto (Ano 11 (2011), No 21, p. 50-62)

3.130. Características fundamentais do processo mnemônico da oralidade primária José Mario Botelho (Ano 10 (2010), N 20 - Suplemento, p. 30-41)

3.131. Cartas de leitores: gênero discursivo porta-voz de queixa, crítica e denúncia no jornal O Dia Solange Garrido da Costa (Ano 5 (2005), № 10, p. 28-41)

3.132. Centenário da universidade brasileira: para a história da Universidade de Manaus (1909/1910-1926)

Eduardo Tuffani (Ano 9 (2009), No 17- Suplemento, p. 64-8-)

3.133. Ciberletramento: multimídia e multimodalidade como propostas de letramento Marcela Cockell (Ano 9 (2009), N 17- Suplemento, p. 81-88) 


\section{Departamento de LetRAS}

3.134. Coelho Neto na rua do Ouvidor: experiência urbana e modernidade no romance brasileiro do final do século XIX

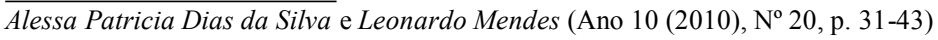

3.135. Coesão e coerência em redações

Nauria Inês Fontana (Ano 5 (2005), No 09, p. 72-86)

3.136. Comandos paragramaticais: o preconceito (socio)linguístico no Brasil

Kleberson da Silva Alves e Jeferson da Silva Alves (Ano 9 (2009), № 17, p. 42-49)

3.137. Comentários ao emprego da crase

Ruy Magalhães de Araujo (Ano 1 (2001), № 01, p. 158-166)

3.138. Comentários sobre a divulgação de obras críticas

Welton da Silva Cordeiro (Ano 10 (2010), $\mathrm{N}^{\circ} 19$ - Suplemento, p. 81-93)

3.139. Comentários sobre as várias edições d'Os Sertões, de Euclides da Cunha - Ruy Magalhães de Araujo (Ano 2 (2002), Nº4, p. 47-56)

3.140. Como a alfabetização carencial afeta a leitura Vicente Martins (Ano 8 (2008), № 15- Suplemento, p. 102-106

3.141. Como a leitura diminui a violência na escola Vicente Martins (Ano 8 (2008), $\mathrm{N}^{\mathrm{o}}$ 15-Suplemento, p. 107-112

3.142. Como as crianças desenvolvem a argumentação infantil

Daniele Pontes Passos; Márcia Rejane Alves Rodrigues; Maria Neuma Freire Araújo; Patrícia Andrade (Ano 8 (2008), № 15-Suplemento, p. 113-116)

3.143. Como as crianças entram no mundo da linguagem Vicente Martins (UVA) (Ano 8 (2008), No 15- Suplemento, p. 117-127

3.144. Como conhecer o cérebro dos disléxicos Vicente Martins (Ano 8 (2008), No 15-Suplemento, p. 128-133)

3.145. Como desenvolver o hábito da leitura de poesia em sala de aula Luciana Cláudia de Castro Olímpio (Ano 8 (2008), № 15- Suplemento, p. 134-142)

3.146. Como entender as principais teorias da LE Francisco de Assis do Nascimento; Jander Ramos Carvalho; Priscila Márcia de Andrade Costa; Rafael Lira Gomes Bastos (Ano 8 (2008), No 15- Suplemento, p. 143147)

3.147. Como formar leitores e escritores competentes Luciana Cláudia de Castro Olímpio (Ano 8 (2008), № 15- Suplemento, p. 88-101)

3.148. Como lidar com as dificuldades da produção de textos em sala de aula Kétilla Maria Vasconcelos Prado; Lady Dayana de Lima e Silva; Maria do Nazaré de Carvalho; Teresinha Rodrigues Alcântara (Ano 8 (2008), No 15- Suplemento, p. 148-153)

3.149. Como melhorar o ensino do português na escola Vicente Martins (Ano 8 (2008), № 15- Suplemento, p. 154-158)

3.150. Como pode o aluno saber matemática sem dominar a língua culta? Vicente Martins (Ano 8 (2008), No 15- Suplemento, p. 159-161) 


\section{FACULDADE DE FORMAÇÃO DE PROFESSORES}

3.151. Como se ensina português no ensino médio Mary Neiva Surdi da Luz (Ano 7 (2007), No 13, p. 26-37)

3.152. Competência comunicativa em língua estrangeira (Que conceito é esse?) Vera Lucia Teixeira da Silva (Ano 4 (2004), Nº 08 - Suplemento, p. 07-17)

3.153. Conhecimento prévio: ativação, construção e suas implicações Rogério da Costa Neves (Ano 5 (2005), N 09, p. 87-98)

3.154. Conjunções adversativas do português Afrânio da Silva Garcia (Ano 11 (2011), No 22, p. 89-113)

3.155. Considerações sobre a Peregrinatio Aetheriae de Rosalvo do Valle José Mario Botelho (Ano 10 (2010), No 19, p. 35-41)

3.156. Considerações sobre as literaturas africanas de expressão portuguesa Dalva Pontes de Almeida, Raquel Pontes de Almeida e Marcelo Moraes Caetano (Ano 9 (2009), No 17, p. 50-61)

3.157. Conteúdos de interpretar: a leitura como passaporte para a interação com o mundo Ilana da Silva Rebello Viegas (Ano 11 (2011), N²2, p. 114-126)

3.158. Contribuição da gramática gerativa no ensino de morfologia derivacional Antônio Sérgio Cavalcante da Cunha (Ano 9 (2009), № 17- Suplemento, p. 89-104)

3.159. Crítica textual e informática: a transmissão dos textos na era digital Charlene Rodrigues Bispo (Ano 10 (2010), No 19 - Suplemento, p. 94-111)

3.160. Crítica textual nos livros didáticos de língua portuguesa Adriana Leite Moreira (Ano 10 (2010), Nº 19 - Suplemento, p. 119-133)

3.161. Crítica textual: edições monotestemunhais e edições politestemunhais Rosa Maria Mendes do Nascimento (Ano 10 (2010), N 19 - Suplemento, p. 112118)

3.162. Da abordagem estrutural ao gerativismo chomskyano Sílvio Ribeiro da Silva (Ano 9 (2009), No 18, p. 83-95)

3.163. De sonhos e devaneios: um olhar sobre as metáforas do amor na MPB e no pop rock Luciana Marino do Nascimento (Ano 10 (2010), No 19, p. 42-47)

3.164. Deslocamento de adjetivos no sintagma nominal do português Afrânio da Silva Garcia (Ano 10 (2010), No 20 - Suplemento, p. 42-65)

3.165. Diálogos sobre mídia e ensino entre professores de letras Núbio Delanne Ferraz Mafra (Ano 8 (2008), Nº 15, p. 160-170)

3.166. Diario del Primer Viaje de Colón: una posibilidad de enseñanza/ aprendizaje de literatura e historia Jeferson da Silva Alves (Ano 9 (2009), № 17- Suplemento, p. 105-110)

3.167. Discurso akwe-xerente: os modos de organização textual voltados para a educação indígena

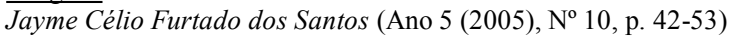

3.168. Discurso e ideologia na aprendizagem do inglês como língua estrangeira William Eduardo da Silva (Ano 4 (2004), 08 - Suplemento, p. 18-25) 


\section{DEPARTAMENTO DE LETRAS}

3.169. Discurso religioso: as ciladas da língua portuguesa Guilherme Dias e Lilian Cristina Granziera (Ano 9 (2009), № 17, p. 62-70)

3.170. Discurso religioso: funções e especificidade Cleide Emilia Faye Pedrosa (Ano 7 (2007), № 13, p. 38-45)

3.171. Discurso sobre a tradução no Brasil Beatriz Fernandes Caldas (Ano 10 (2010), № 20, p. 44-52)

3.172. Discutindo os critérios para a definição de sujeito no português do Brasil - Antônio Sérgio Cavalcante da Cunha (Ano 5 (2005), № 10, p. 97-106)

3.173. Documento: bases analíticas da ortografia simplificada da língua portuguesa de 1945, renegociadas em 1975 e consolidadas em 1986 (Ano 11 (2011), N N $^{\mathrm{O}}$ 21, p. 159$\underline{171)}$

3.174. Dos fantásticos ao Fantástico:: um percurso por teorias do gênero Flavio García e Angélica Maria Santana Batista (Ano 5 (2005), No 10, p. 107-115)

3.175. E agora, José? As poesias de Drummond: 1918-1930 Maria Lucia Mexias-Simon (Ano 10 (2010), No 19 - Suplemento, p. 134-140)

3.176. EaD para todos: gestão de cursos a distância Marcelo Moraes Caetano; Luisa Fontes Staib; Tatyana Porto Diolino; Valéria Cristina Gomes Lyrio Aguiar (Ano 9 (2009), № 17- Suplemento, p. 111-120)

3.177. Ecdótica: uma abordagem panorâmica dos principais tipos de edição Beatriz da Silva (Ano 10 (2010), No 19 - Suplemento, p. 141-148)

3.178. Edição dos sermões de dom frei Domingos da Transfiguração Machado, do mosteiro de São Bento da Bahia Marília Andrade Nunes e Alícia Duhá Lose (Ano 10 (2010), № 20 - Suplemento, p. 66-76)

3.179. Em busca da fluência oral: um curso de Letras sub judice Vera Lúcia Teixeira da Silva (Ano 8 (2008), № 16 - Suplemento, p. 164-194)

3.180. Ensaio sobre a posse Tânia Pereira (Ano 2 (2002), № 03, p. 134-142)

3.181. Ensino de produção escrita do gênero resenha crítica: a atuação do professor e do livro didático de português Sílvio Ribeiro da Silva (Ano 11 (2011), No 22, p. 127-136)

3.182. Ensino e aprendizagem da ortografia na escola Vicente Martins (Ano 8 (2008), N ${ }^{\circ} 15$ - Suplemento, p. 162-169)

3.183. Então e agora na conversa informal Sandra Bernardo (Ano 3 (2003), Nº 05-06, p. 65-81)

3.184. Entre a tradição e a prodigalidade: estudo dos gêneros em Lavoura Arcaica Lúcia Liberato Evangelista e Douglas de Paula (Ano 7 (2007), No 14, p. 121-130)

3.185. Episódio e evento na organização tópica da conversa informal Sandra Bernardo (Ano 1 (2001), No 01, p. 34-49) 


\section{FACULDADE DE FORMAÇÃo dE PROFESSORES}

3.186. Episódios da história de Portugal n'Os Lusíadas Maria Paula Lamas (Ano 6 (2006), No 12, p. 64-75)

3.187. Eros: um foco de luz na obra poética de Florbela Espanca Maria Alice Aguiar (Ano 2 (2002), No 03, p. 55-64)

3.188. Estrangeirismos de língua inglesa (o caso dos antropônimos) Antônio Elias Lima Freitas (Ano 7 (2007), No 14, p. 131-162)

3.189. Estrangeirismos na internet: a força de atuação das lan houses no processo de cristalização de expressões do inglês Jhonatta Costa e Silva (Ano 10 (2010), No 19, p. 21-34)

3.190. Estratégias facilitadoras da leitura de textos acadêmicos em inglês como língua estrangeira (ILE) Solange Garrido da Costa (Ano 3 (2003), Nº5-06, p. 82-95)

3.191. Estratégias linguístico-discursivas na obra de Adriana Falcão: o amálgama da linguagem e narrativa Anete Mariza Torres Di Gregorio (Ano 4 (2004), № 08, p. 106-119)

3.192. Estrutura da oração Luci Mary (Ano 4 (2004), Nº8, p. 120-128)

3.193. Estrutura tópico-comentário, a tradicão gramatical e o ensino de redacão Antônio Sérgio Cavalcante da Cunha (Ano 10 (2010), No 20, p. 53-63)

3.194. Estudo dos advérbios modalizadores em -mente na linguagem jornalística Anete Mariza Torres Di Gregorio (Ano 4 (2004), № 08, p. 129-139)

3.195. Estudo sobre o aspecto verbal no pretérito perfeito simples e pretérito perfeito composto Marcela Cockell (Ano 10 (2010), No 19, p. 48-59)

3.196. Eu acho impossivel colocar em prática, mas eu queria: pensando em uma abordagem de gêneros para o ensino de inglês

Isabel Cristina Rangel Moraes Bezerra (Ano 8 (2008), No 16 - Suplemento, p. 97 125)

3.197. Experimentos psicolinguísticos na área de processamento lexical: a influência das características das línguas na configuração e resultados experimentais Antônio Sérgio Cavalcante da Cunha (Ano 4 (2004), Nº 08, p. 140-148)

3.198. Fábulas de outono: uma leitura de Cortejo em Abril, de Zulmira Tavares Maria Aparecida Rodrigues Fonte (Ano 1 (2001), Nº 01, p. 56-72)

3.199. Falando sobre Não Falei, de Beatriz Bracher Carlos Eduardo da Cruz (Ano 10 (2010), N 19 , p. 60-79)

3.200. Filologia e linguística: encontros e desencontros Munniky Müller (Ano 10 (2010), No 19 - Suplemento, p. 149-155)

3.201. Fontes do latim vulgar Ruy Magalhães de Araujo (Ano 3 (2003), № 05-06, p. 96-115) 


\section{DEPARTAMENTO DE LETRAS}

3.202. Formação de formadores:: o docente do ensino superior é um profissional da educação

Paula Cancella Januario (Ano 7 (2007), № 13, p. 46-58)

3.203. Gênero textual e tipologia textual: colocações sob dois enfoques teóricos

Sílvio Ribeiro da Silva (Ano 10 (2010), N 20, p. 64-75)

3.204. Gêneros e tipos: uma aproximação

Mara Lucia Fabrício de Andrade (Ano 1 (2001), № 02, p. 83-92)

3.205. Gregório de Matos, o sagrado e o barroco José Pereira da Silva (Ano 7 (2007), No 14, p. 163-177)

3.206. Heterônimos do passado e do futuro Maria de Lourdes Soares (Ano 7 (2007), № 13, p. 59-64)

3.207. Identidades em ruínas: uma leitura de Estorvo, de Chico Buarque Ilma da Silva Rebello (Ano 7 (2007), No 14, p. 178-184)

3.208. Incursões pelo o conceito de sujeito nos estudos gramaticais Gislaine Aparecida de Carvalho e Albano Dalla Pria (Ano 10 (2010), No 20 - Suplemento, p. 77-84)

3.209. Índice da Soletras até o número 22 José Pereira da Silva (Ano 11 (2011), № 22, p. 137-162)

3.210. Inês de Castro: corpo-texto nos diálogos literários Brasil-Portugal Roberto Nunes Bittencourt (Ano 8 (2008), No 15, p. 171-178)

3.211. Iniciação às investigações sobre anguladores Angelina Aparecida de Pina (Ano 5 (2005), No 10, p. 54-61)

3.212. Introdução ao pragmatismo linguístico Jorge da Silva e Vera Lúcia T. da Silva (Ano 1 (2001), No 01, p. 125-139)

3.213. Jornal impresso e ensino de língua: uma abordagem discursiva do texto jornalístico Joana Darc O. Canonico (Ano 4 (2004), № 08 - Suplemento, p. 26-39)

3.214. Jornalismo e literatura - a composição das memórias navianas Edina Regina P. Panichi (Ano 9 (2009), № 18, p. 96-107)

3.215. La escala de préstamos de Sarah Thomason y el contacto español-portugués en el sur de Brasil María Josefina Israel Semino de Lopez(Ano 6 (2006), № 11, p. 48-63)

3.216. La questione della lingua in Italia Flora Simonetti Coelho (Ano 3 (2003), No 05-06, p. 116-123)

3.217. La teoría literaria y la filosofia en la heteronomía del lenguaje: Una lectura deconstructiva

Olga M. Tiberi (Ano 5 (2005), No 09, p. 99-110)

3.218. Leitores e leituras: uma construção progressiva nunca acabada Lucia Helena Lopes de Matos (Ano 4 (2004), № 07, p. 59-69)

3.219. Leituras \& leitura de literatura ou o (re)nascimento do leitor Maria Cristina Ribas (Ano 8 (2008), N 16 - Suplemento, p. 59-76) 


\section{FACULDADE DE FORMAÇÃo dE PROFESSORES}

3.220. Lendo e escrevendo com prazer, professores e alunos revisitam Monteiro Lobato Maria Alice Aguiar (Ano 5 (2005), Nº9, p. 111-120)

3.221. Letramento acadêmico: a construção de paráfrases em resenhas Victoria Wilson e Adriana Rodrigues Abreu (Ano 10 (2010), № 20, p. 76-90)

3.222. Linguagens, Identidades, Ensino: Modos de Pensar, Modos de Fazer (Ano 8 (2008), $\mathrm{N}^{\circ} 16$ - Suplemento, $227 \mathrm{p}$.)

3.223. Literatura e adaptação cinematográfica: diferentes linguagens, diferentes leituras Flávio Freire e Renata Zaninelli (Ano 8 (2008), No 15, p. 179-186)

3.224. Literatura e leitores: estratégias acionais no processo de formação do leitor Marcello de Oliveira Pinto (Ano 5 (2005), № 10, p. 139-149)

3.225. Literatura e mídia: pactos miméticos na contemporaneidade Ana Cristina Coutinho Viega (Ano 8 (2008), No 16, p. 23-29)

3.226. Literatura infantil: qual a sua contribuição para o desenvolvimento da leitura nas séries iniciais?

Ariana Lourenço da Silva (Ano 8 (2008), No 16, p. 30-38)

3.227. Literatura no singular/Literatura no plural: notas sobre o livro Ó Fala que Foste Fala Maria Isaura Rodrigues Pinto (Ano 10 (2010), № 20 - Suplemento, p. 197-202)

3.228. Literatura, história e pós-modernidade: trilhas possíveis? Marcello de Oliveira Pinto (Ano 3 (2003), № 05-06, p. 124-138)

3.229. Lucia McCartney e a história literária como disrupção Luiz Antonio Garcia Diniz (Ano 10 (2010), No 20, p. 91-104)

3.230. Machado de Assis e a estética da recepção Marillia Raeder Auar Oliveira (Ano 7 (2007), № 14, p. 185-195)

3.231. Machado de Assis orquestrando a iluminação e a opacidade em "Cantigas de Esponsais"

Maria Alice Aguiar. (Ano 2 (2002), № 04, p. 57-69)

3.232. Machado de Assis: dimensão diacrônica de alguns aspectos do pessimismo Ruy Magalhães de Araujo (Ano 2 (2002), No 03, p. 07-30)

3.233. Manoel de Barros: os "despropósitos" da poesia Bianca Albuquerque da Costa (Ano 8 (2008), Nº 16, p. 39-47)

3.234. Manual Prático de Latim Medieval: Antologia do latim medieval - Dag Norberg. Tradução de José Pereira da Silva (Ano 6 (2006), No 12 - Suplemento, 116 p.)

3.235. Manual Prático de Latim Medieval: Breve história do latim medieval - Dag Norberg. Tradução de José Pereira da Silva (Ano 6 (2006), № 12 - Suplemento, 127 p.)

3.236. Mapeando trabalhos acadêmicos: os agradecimentos como atos de fala Cleide Emília Faye Pedrosa e Cleide Selma de Souza Matos (Ano 9 (2009), № 17, p. 71-83)

3.237. Mario de Andrade nacional, tradicional e moderno Marcia Reis(Ano 6 (2006), No 11, p. 64-73) 


\section{DEPARTAMENTO DE LETRAS}

3.238. Memória e identidade no romance contemporâneo Regina Pentagna Petrillo (Ano 8 (2008), No 16, p. 48-56)

3.239. Memórias, repertórios, descontinuidades, onde as rupturas? Iza Quelhas (Ano 3 (2003), No 05-06, p. 139-153)

3.240. Mitocrítica portuguesa: na crise finissecular, o reflorescer de mitos Roberto Nunes Bittencourt (Ano 11 (2011), № 22, p. 163-179)

3.241. Modos de ler o discurso religioso Victoria Wilson (Ano 3 (2003), N ${ }^{\circ}$ 05-06, p. 154-159)

3.242. Momentos brasileiros no processo de criação de Elizabeth Bishop Sílvia M. Guerra Anastácio (Ano 2 (2002), Nº3, p. 65-74)

3.243. Morte e vida PROEJA: leitura, escrita e experiência de vida Aytel Marcelo Teixeira da Fonseca e José Enildo Elias Bezerra (Ano 11 (2011), № $\underline{21, \text { p. } 63-70)}$

3.244. Mosaicos epistolares na MPB Luciana M. do Nascimento e João Gabriel Lopes de Brito (Ano 11 (2011), № 21, p. $\underline{71-81)}$

3.245. Mulheres que matam: a memória traumática em Beloved Bárbara Inês Ribeiro Simões Daibert (Ano 9 (2009), $\mathrm{N}^{\circ} 18$, p. 108-116)

3.246. Multiculturalismo crítico por uma pedagogia da tolerância Patrícia Carvalho de Onofre (Ano 9 (2009), № 17- Suplemento, p. 121-127)

3.247. Nascemos ou não com uma pré-disposição para a linguagem? Márcia Rejane Alves Rodrigues (Ano 8 (2008), N 15-Suplemento, p. 170-173)

3.248. Neurociência, cognição e dislexia Vicente Martins (Ano 8 (2008), $\mathrm{N}^{\circ}$ 15- Suplemento, p. 174-187)

3.249. Nominalização, memória discursiva e argumentação Hilda de Oliveira Olímpio (Ano 6 (2006), № 12, p. 76-87)

3.250. Nota pelos cem anos do ensino superior de filosofia no Brasil (1908-2008) Eduardo Tuffani (Ano 10 (2010), № 20 - Suplemento, p. 168-184)

3.251. OAlienista: análise das variantes do folhetim e do livro Jaison Luís Crestani (Ano 10 (2010), № 19 - Suplemento, p. 156-166)

3.252. $\mathrm{O}$ angustiado homem do ressentimento em Graciliano Ramos Renato Nunes Bittencourt (Ano 8 (2008), No 16, p. 57-68)

3.253. O barroco mineiro em Drummond Fernando Monteiro de Barros (Ano 2 (2002), № 03, p. 143-156)

3.254. O Barroco no Brasil: Gregório de Matos e Vieira José Pereira da Silva (Ano 5 (2005), Nº9, p. 121-130)

3.255. O comportamento sintático das conjunções causais/explicativas Antônio Sérgio Cavalcante da Cunha (Ano 1 (2001), No 02, p. 20-38) 


\section{FACULDADE DE FORMAÇÃO DE PROFESSORES}

3.256. O conectivo quando na fase arcaica do português

Maria Regina Pante e Valéria Adriana Maceis (Ano 9 (2009), № 17, p. 84-91)

3.257. O conhecimento linguístico no processo de avaliação textual Alex Swander (Ano 6 (2006), No 12, p. 88-97)

3.258. O coração da escola: perspectiva interacional das práticas discursivas Maria do Rosario Roxo (Ano 8 (2008), No 16 - Suplemento, p. 126-147)

3.259. O cordel do Brasil e o cordel de Portugal: possíveis diálogos Maria Isaura Rodrigues Pinto (Ano 9 (2009), No 18, p. 117-132)

3.260. O desamparo do leitor: o romance modernista na sala de aula de literatura Leonardo Mendes (Ano 8 (2008), No 16 - Suplemento, p. 40-58)

3.261. O desenvolvimento das línguas ibéricas e a política linguística do governo central espanhol Geraldo Alves Teixeira Júnior (Ano 9 (2009), № 17- Suplemento, p. 128-147)

3.262. O despertar da Bela Adormecida em $O$ Barão de Branquinho da Fonseca Maria Alice Aguiar (Ano 1 (2001), No 01, p. 140-157)

3.263. O discurso da mídia sobre a autoajuda Alessandra Freitas da Silva (Ano 9 (2009), № 17, p. 92-118)

3.264. O emprego do cd O Cortiço: Uma Metodologia para Estimular a Leitura Robson Pereira Gonçalves; Carolina de Andrade Cosme; Daiane Antunes Dias; Marina da Silva Bordin (Ano 2 (2002), No 03, p. 75-84)

3.265. O enfoque instrumental na leitura Sérgio Nascimento de Carvalho (Ano 5 (2005), No 10, p. 116-129)

3.266. O engajamento político-social na poesia bucólica de Virgílio, Calpúrnio e Nemesia$\underline{\text { no }}$ Ivone da Silva Rebello (Ano 4 (2004), No 07, p. 70-85)

3.267. O ensino da língua portuguesa na escola: o trabalho com textos Alexandre Henrique Delpech (Ano 6 (2006), No 12, p. 96-104)

3.268. O ensino de leitura em língua materna a partir do desenvolvimento de estratégias de leitura em língua estrangeira Rogério da Costa Neves (Ano 3 (2003), № 05-06, p. 160-175)

3.269. O erotismo acima de tudo em Antônio Cícero José Heronides Andrade de Moura (Ano 1 (2001), № 02, p. 112-117)

3.270. O gênero dos substantivos: derivação ou flexão? José Mario Botelho (Ano 4 (2004), No 07, p. 86-92)

3.271. O mal-do-século no romantismo inglês Fernando Monteiro de Barros (Ano 4 (2004), No 08, p. 149-159)

3.272. O mentalismo, o empirismo e o funcionalismo nos estudos da linguagem Fábio Bonfim Duarte (Ano 1 (2001), No 02, p. 39-46)

3.273. O mito da saudade: ambivalência criativa em Teixeira de Pascoaes Roberta Almeida Prado de Figueiredo Ferraz (Ano 7 (2007), N ${ }^{\circ} 13$, p. 65-76) 


\section{DEPARTAMENTO DE LETRAS}

3.274. O Nome da Rosa de Umberto Eco: questões em torno do (pós?)-moderno Maria Cristina Ribas; Gabriel Guerreiro da Fonseca; Lidiane dos Santos Souza; Vagner Leite Rangel (Ano 10 (2010), N 20 - Suplemento, p. 85-95)

3.275. O papel social da língua: o poder das variedades linguísticas Carmen Elena das Chagas (Ano 8 (2008), N 16, p. 69-74)

3.276. O poder da interpretação Mabel Pessoa Spindola (Ano 2 (2002), № 03, p. 85-92)

3.277. O poder da literatura moralizadora de padre Antônio Vieira e o conflito do homem barroco em Gregório de Matos

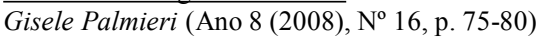

3.278. O português do Brasil - questões de substrato, superstrato e adstrato Afrânio da Silva Garcia(Ano 2 (2002), Nº4, p. 70-80)

3.279. O Pós-Modernismo nas histórias em quadrinhos Afrânio Garcia (Ano 5 (2005), No 10, p. 130-138)

3.280. O prefácio de um retrato Marcello de Oliveira Pinto (Ano 4 (2004), № 07, p. 93-102)

3.281. O produto (marca) como garoto-propaganda: as modalidades do ato delocutivo e a intertextualidade uma leitura semiolinguística do texto publicitário escrito Ilana da Silva Rebello (Ano 6 (2006), No 11, p. 74-87)

3.282. O projeto literário de António Alves Redol e o seu destinatário: nota sobre a aurora do neorrealismo literário português Antony Cardoso Bezerra (Ano 11 (2011), No 21, p. 180-192)

3.283. O prologus do livro I da Utopia de Morus Ricardo Hiroyuki Shibata (Ano 2 (2002), № 03, p. 93-111)

3.284. O pronome nenhum e a dupla negação portuguesa: uma trajetória de gramaticalização? Adriana dos Santos Souza e Maria Regina Pante (Ano 6 (2006), № 12, p. 105-115)

3.285. O que influencia a aquisição da fala nas crianças Márcia Rejane Alves Rodrigues; Maria Neuma Freire Araújo (Ano 8 (2008), No 15 Suplemento, p. 188-191

3.286. O Rio de Janeiro no fim do século XIX: modernidade, boemia e o imaginário republicano no romance de Coelho Neto Elton Nunes e Leonardo Mendes (Ano 8 (2008), № 16, p. 81-96)

3.287. O século XVI e sua problemática linguística Eduardo de Almeida Navarro (Ano 4 (2004), № 08, p. 160-166)

3.288. O silenciar de eros e psique em Mago e Madalena, de Miguel Torga Regina Michelli (Ano 1 (2001), $\mathrm{N}^{\circ}$ 01, p. 98-105)

3.289. O social e o literário: a apropriação de valores morais da sociedade ibérica do XVII feita por uma sátira atribuída a Gregório de Matos Eduardo da Silva de Freitas (Ano 7 (2007), No 14, p. 196-208) 


\section{FACULDADE DE FORMAÇÃo dE PROFESSORES}

3.290. O tempo parou a crise da modernidade em Esperando Godot, de Samuel Beckett Carlos Eduardo Soares da Cruz; Camilla Canella Moraes; Leonardo Pinto Mendes (Ano 5 (2005), No 09, p. 131-143)

3.291. O triunfo da picaretagem em Moll Flanders, de Daniel Defoe Loraci Hofmann Tonus (Ano 8 (2008), N 16, p. 97-107)

3.292. O último dos moicanos: protótipo da aventura romântica Loraci Hofmann Tonus e Márcia Oberderfer Consoli (Ano 9 (2009), № 17, p. 119130)

3.293. Observações sobre construção de conhecimento Regina Maria de Britto Figueiredo (Ano 7 (2007), № 13, p. 77-96)

3.294. Os "ditos políticos" nas máximas de Grice: uma análise Ana Maria Dal Zott Mokva (Ano 1 (2001), No 02, p. 47-57)

3.295. Os dois textos de o Seminarista de Bernardo Guimarães Luana Batista de Souza (Ano 10 (2010), Nº 19 - Suplemento, p. 167-178)

3.296. Os falsos amigos: português e espanhol Jeferson da Silva Alves (Ano 8 (2008), № 16, p. 108-116)

3.297. Os Fastos: festas e rituais pagãos dedicados à deusa Ana Perena Eliana da Cunha Lopes (Ano 10 (2010), № 19, p. 80-90)

3.298. Os passados no ensino de português para estrangeiros Vanise Gomes de Medeiros (Ano 1 (2001), Nº 02, p. 76-82)

3.299. Os quase-fonemas do português Afrânio da Silva Garcia(Ano 2 (2002), No 04, p. 81-87)

3.300. Os risos em Aparício Torelly, o barão de Itararé Mary Stela Surdi (Ano 6 (2006), N 12, p. 116-127)

3.301. Os significados afetivos em textos escolares Victoria Wilson (Ano 8 (2008), № 16 - Suplemento, p. 195-212)

3.302. Os verbos dicendi na construção de personagens da literatura brasileira Ilana da Silva Rebello Viegas (Ano 8 (2008), № 16, p. 117-128)

3.303. Palavras à margem, poetas excêntricos: a produção teórica e poética de Cacaso Iza Quelhas (Ano 4 (2004), $\mathrm{N}^{\circ}$ 08, p. 167-176)

3.304. Para uma bibliografia da história da língua portuguesa José Pereira da Silva (Ano 10 (2010), N 20 - Suplemento, p. 96-149)

3.305. Para uma edição da obra reunida de Hugo de Carvalho Ramos Albertina Vicentini (Ano 10 (2010), N 19 - Suplemento, p. 179-195)

3.306. Parceiros da noite: gays e vampiros na literatura Fernando Monteiro de Barros (Ano 1 (2001), No ${ }^{\circ}$ 02, p. 118-128)

3.307. Paul Teyssier e o teatro de Camões Leodegário A. de Azevedo Filho (Ano 2 (2002), No 03, p. 112-118) 


\section{DEPARTAMENTO DE LETRAS}

3.308. Pelos afluentes da escrita: o fazer literário na visão de cinco jovens escritoras Fernanda Paixão; Karine Aragão; Katiane de Carvalho; Mariana Andrade; Patricia Teixeira (Ano 7 (2007), No 14, p. 209-228)

3.309. Pelos becos e pela avenida da bélle époque carioca Marcela Cockell Mallmann (Ano 10 (2010), № 20, p. 105-118)

3.310. Peregrinação de Ulisses e de Vasco da Gama Maria Paula Lamas (Ano 7 (2007), Nº 13, p. 97-105)

3.311. Pérolas recolhidas de Gregório de Mattos e Guerra Ruy Magalhães de Araujo (Ano 10 (2010), No 19 - Suplemento, p. 196-198)

3.312. Perspectivas linguísticas: divergentes ou complementares? Diognes Ramos Marchon (Ano 10 (2010), No 19, p. 91-108)

3.313. Poesia é voar fora da asa: os limites do ensino da leitura Maria Cristina Ribas (Ano 9 (2009), No 17- Suplemento, p. 148-162)

3.314. Polissemia versus homonímia: a (in)validade de conceitos em questão Márcio Ribeiro dos Santos (Ano 4 (2004), No 08, p. 177-180)

3.315. Políticas da voz no discurso político: efeitos da substância da expressão no horário de propaganda eleitoral gratuita Carlos Piovezani Filho (Ano 7 (2007), No 13, p. 106-117)

3.316. Pomosexuals: a literatura pós-moderna das minorias sexuais Eliane Borges Berutti (Ano 1 (2001), No 01, p. 106-112)

3.317. Por uma proposta para a didatização de gêneros no ensino fundamental Sílvio Ribeiro da Silva (Ano 11 (2011), No 21, p. 82-93)

3.318. Práticas (de ensino) em literatura e jornal: quem quer integrar este coro? Maria Cristina Ribas (Ano 4 (2004), No 07, p. 103-117)

3.319. Preconceito: linguístico ou social? Luciana Morais da Silva (Ano 7 (2007), № 13, p. 118-128)

3.320. Presença de anguladores em textos de jornal: seguramente, uma espécie de pesquisa verdadeiramente relevante

Vito César de O. Manzolillo (Ano 2 (2002), №3, p. 119-133)

3.321. Pronomes indefinidos Afrânio da Silva Garcia (Ano 10 (2010), № 19, p. 109-116)

3.322. Raízes do popular na escritura rosiana Maria Isaura Rodrigues Pinto (Ano 4 (2004), № 08, p. 181-189)

3.323. Reclamação: uma questão de afeto e interação Victoria Wilson (Ano 1 (2001), $\mathrm{N}^{\mathrm{o}}$ 02, p. 58-65)

3.324. Recursos de expressividade em aulas Paulo de Tarso Galembeck (Ano 10 (2010), № 20, p. 119-130)

3.325. Reflexão e conflito na poesia de Alberto Caeiro Vitor Henriques (Ano 7 (2007), No 13, p. 129-140) 


\section{FACULDADE DE FORMAÇÃO DE PROFESSORES}

3.326. Reflexões sobre a evasão às sextas feiras no contexto da escola pública Neide Batista da Silva (Ano 6 (2006), N 11, p. 88-104)

3.327. Reflexões sobre a função sintática de atributo Antônio Sérgio Cavalcante da Cunha (Ano 9 (2009), № 18, p. 133-138)

3.328. Reflexões sobre coordenação e subordinação Sandra Bernardo (Ano 4 (2004), No 07, p. 118-129)

3.329. Reflexões sobre o objeto direto, o objeto indireto e o adjunto circunstancial, na cla ssificação sintática dos termos da oração, de Mário Perini Antônio Sérgio Cavalcante da Cunha (Ano 7 (2007), № 13, p. 141-151)

3.330. Relação da linguagem com a filosofia e antropologia filosófica Miguél Eugenio Almeida (Ano 6 (2006), N 11, p. 105-112)

3.331. Remate de Males: a louvaccão improvisada de Mário de Andrade Tatiana Alves Soares Caldas (Ano 5 (2005), № 10, p. 69-74)

3.332. Renascimento do hebraico: a busca pela identidade de um povo Thiago Humberto do Nascimento (Ano 5 (2005), $\mathrm{N}^{\circ}$ 09, p. 144-153)

3.333. Representações do feminino em O primo Basílio e Dom Casmurro Linda Catarina Gualda (Ano 7 (2007), № 13, p. 152-170)

3.334. Representações do feminino em The Turn of the Screw: a governanta como anjo do lar e monstro à solta

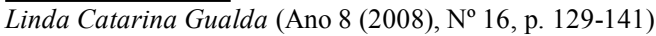

3.335. Retomando a discussão: grau - flexão x grau - derivação Alexandre Melo de Sousa (Ano 8 (2008), No 16, p. 142-156)

3.336. Retratos de fadas e bruxas Armando Gens (Ano 1 (2001), No 01, p. 50-55)

3.337. Rio/Homem: cursos e discursos na poesia de João Cabral Maria Isaura Rodrigues Pinto (Ano 3 (2003), № 05-06, p. 176-185)

3.338. Rios cifrados na rua: Leituras de trabalhadores em São Gonçalo Iza Quelhas (Ano 8 (2008), № 16 - Suplemento, p. 12-39)

3.339. Rubem Fonseca e as publicações do novo século Leonardo Barros Medeiros (Ano 10 (2010), $\mathrm{N}^{\circ} 20$ - Suplemento, p. 150-167)

3.340. Rubem Fonseca e Irmãos Campos: reflexões sobre leitura e traducão Luciana de Mesquita Silva (Ano 6 (2006), No 12, p. 128-139)

3.341. Semântica histórica Afrânio Garcia (Ano 1 (2001), No 02, p. 66-75)

3.342. Semiótica \& ensino: estratégias para a leitura e textualização Darcilia Simões (Ano 4 (2004), Nº7, p. 130-140)

3.343. Ser Poeta: imagens da metapoesia em Florbela Espanca André Luiz Alves Caldas Amóra (Ano 5 (2005), No 10, p. 75-84) 


\section{DEPARTAMENTO DE LETRAS}

3.344. Shirley Jackson: uma apresentação necessária

Gustavo Vargas Cohen (Ano 11 (2011), № 22, p. 193-200)

3.345. Sobre o latim e outros latins: algumas reflexões sociolinguísticas

Leila Teresinha Maraschin (Ano 7 (2007), No 14, p. 229-238)

3.346. Sobre realidades e realismos em Gabriel García Márquez: alguns contrapontos dissonantes

Maria Aparecida da Silva (Ano 6 (2006), № 12, p. 140-154)

3.347. Sociedade, identidade e lingua(gem) na educação de jovens e adultos Juliana Sousa Trajano (Ano 11 (2011), No 21, p. 94-109)

3.348. Sociolinguística cultural

Marcelo Moraes Caetano (Ano 10 (2010), №20, p. 131-145)

3.349. Socrates currit bene: um breve passeio pela história da gramática Elisa Figueira de Souza Corrêa (Ano 10 (2010), Nº 19, p. 116-123)

3.350. Teorias semânticas

Nauria Inês Fontana (Ano 4 (2004), No 07, p. 141-145)

3.351. Texto e leitor na ficção brasileira: perspectivas e impasses

Maria Isaura Rodrigues Pinto (Ano 8 (2008), No 16 - Suplemento, p. 77-96)

3.352. Tipologia linguística: línguas analíticas e línguas sintéticas

Albano Dalla Pria (Ano 6 (2006), № 11, p. 113-121)

3.353. Tipos de discurso

Afrânio Garcia (Ano 3 (2003), No 05-06, p. 186-190)

3.354. Trabalhando com literatura de cordel no ensino fundamental: relato de uma vivência Marcella Braga Cobian; Mariana Fernandes de Lima Costa; Maria Isaura Rodrigues Pinto (Ano 11 (2011), No 21, p. 110-116)

3.355. Trabalho acadêmico: espaço discursivo de polifonização ou monofonização? Cleide Emilia Faye Pedrosa; Cleide Selma de Souza Matos; Sônia Pinto de Albuquerque Melo (Ano 8 (2008), No 15, p. 187-195)

3.356. Traços decadentistas em Olavo Bilac e Emiliano Perneta Fernando Monteiro de Barros; Armando Rabelo Soares Neto; Ingrid Moura Carlos (Ano 9 (2009), $\mathrm{N}^{\circ} 17$ - Suplemento, p. 163-174)

3.357. Traços do decadentismo na poesia brasileira de 1880 a 1920: Raimundo Correia e Gilka Machado Fernando Monteiro de Barros; Aline Pereira; Suzane Morais da Veiga (Ano 10 (2010), No 19 , p. 124-135)

3.358. Três lemas, duas lutas, um flagelo: Galícia e Queimados Phellipe Marcel da Silva Esteves (Ano 7 (2007), No 13, p. 171-183)

3.359. Um breve comentário sobre os relatos de viagens e as citações na obra Os Ensaios, de Michel de Montaigne Antonio Carlos Lopes Petean (Ano 10 (2010), No 20 - Suplemento, p. 203-209) 


\section{FACULDADE de FormaÇÃo de PROFESSORES}

3.360. Um dicionário tupi de 1771 como crônica da situação linguística na Amazônia pombalina

Maria Cândida Drumond Mendes Barros; Antônio Luís Salim Lessa (Ano 4 (2004), $\mathrm{N}^{\mathrm{o}} 08$ - Suplemento, p. 40-51)

3.361. Um dramaturgo alto: pós-modernidade e morte em Three tall women, de Edward Albee

Leonardo Mendes (Ano 4 (2004), No 07, p. 146-155)

3.362. Um pouco de digressões acerca da complementação verbal José Mario Botelho (Ano 11 (2011), № 21, p. 117-133)

3.363. Um relato de trabalho com leitura/redação em língua portuguesa na educação de jovens e adultos (EJA)

Aytel Marcelo Teixeira da Fonseca ; Antônio Sérgio Cavalcante da Cunha (Ano 7 (2007), No 14 , p. 238-256)

3.364. Uma análise ecdótica da edicão da "Oracão aos Moços" de Rui Barbosa Ana Paula da Silva Freitas (Ano 10 (2010), No 19 - Suplemento, p. 199-223)

3.365. Uma análise funcionalista sobre o uso dos satélites fonte em notícias "on-line" André William Alves de Assis (Ano 11 (2011), No 21, p. 134-146)

3.366. Uma anatomia da verdade sobre a educação neste país Alex Swander (Ano 8 (2008), No 15, p. 196-202)

3.367. Uma avaliação do primeiro ano de implantação do novo Acordo Ortográfico da Língua Portuguesa

José Pereira da Silva (Ano 10 (2010), № 19, p. 136-148)

3.368. Uma estrela que atravessa o tempo: Outro Pé da Sereia, de Mia Couto Carlos Eduardo Soares da Cruz(Ano 8 (2008), No 15, p. 203-211)

3.369. Uma experiência de promoção da leitura/escrita na Educação de Jovens e Adultos (EJA) Aytel Marcelo Teixeira da Fonseca; Antônio Sérgio Cavalcante da Cunha (Ano 8 (2008), No 15 , p. 212-224)

3.370. Uma louca criação: Suze Salomé Letícia Pereira de Andrade (Ano 6 (2006), No 11, p. 122-130)

3.371. Uma tipologia semântica do verbo no português Afrânio da Silva Garcia (Ano 4 (2004), N 08 - Suplemento, p. 52-70)

3.372. Uma trajetória sobre o estatuto sintático do SN em direção ao conceito de convergência Bruna Karla Pereira (Ano 9 (2009), No 17, p. 131-141)

3.373. Una secuencia de apropiacion de la ortografia del portugués Jaime Luiz Zorzi (Ano 8 (2008), № 15- Suplemento, p. 192-220)

3.374. Utilizando a poesia no ensino de português Afrânio da Silva Garcia (Ano 4 (2004), No 08 - Suplemento, p. 71-75)

3.375. Verbos designativos no português Afrânio da Silva Garcia (Ano 1 (2001), № 01, p. 113-124) 


\section{DEPARTAMENTO DE LETRAS}

3.376. Verbos incompatíveis com o progressivo: estudo comparativo do inglês e do português

Afrânio da Silva Garcia (Ano 10 (2010), № 20, p. 146-164)

3.377. Verbos leves: observações sobre o português do Brasil

Nataniel dos Santos Gomes (Ano 4 (2004), No 08 - Suplemento, p. 76-83)

3.378. Verbos-suporte ou expressões lexicalizadas?

Hilda Monetto Flores da Silva (Ano 9 (2009), № 17- Suplemento, p. 1175-182)

3.379. Verdade e fragmento: o diário como "pseudogênero" em Bolor de Augusto Abelaira Marcos Fiuza (Ano 8 (2008), No 16, p. 169-176)

3.380. Viagem ao Brasil de Alexandre Rodrigues Ferreira José Pereira da Silva(Ano 6 (2006), № 11, p. 131-143)

3.381. Victor Leal e o romance-folhetim no Rio de Janeiro no final século XIX Leonardo Mendes e Andréa Gonçalves da Silva (Ano 11 (2011), Nº 22, p. 201-209)

3.382. Victor Silva, poeta decadentista

Fernando Monteiro de Barros (Ano 10 (2010), № 20, p. 165-176)

3.383. Vida e obra do "maior artista do verso" no Brasil: breves notas no centenário de seu falecimento Antônio Martins de Araújo (Ano 11 (2011), № 22, p. 210-216)

3.384. Visões do Rio de Janeiro nas crônicas de Joaquim Manoel de Macedo e João do Rio e suas projecões no ensino de literatura

Maria Cristina Ribas; Carolina Santiago; Rafaela Ramos (Ano 11 (2011), No 21, p. $\underline{147-158)}$

3.385. Vocabulário cristão: estudo da onomasiologia em três tratados medievais Rita de Cássia Ribeiro de Queiroz (Ano 6 (2006), No 11, p. 144-156)

3.386. Vontade rebelada em Rubem Fonseca: uma leitura nietzschiana Gisele Batista da Silva (Ano 7 (2007), Nº 13, p. 184-192)

3.387. Vozes de África

Fátima Helena Azevedo de Oliveira (Ano 1 (2001), No 02, p. 129-136)

3.388. Vozes verbais: do discurso ao aprendizado

Márcio Ribeiro dos Santos (Ano 8 (2008), No 16, p. 177-191)

\section{Conclusão}

Desde a criação deste já prestigiado periódico até o presente número, a Coordenação de Publicações do Departamento de Letras nunca foi alterada e todas as edições dela proveniente foram preparadas, produzidas e divulgadas sem qualquer custo para a Universidade do Estado do Rio de Janeiro ou para o próprio Departamento, pois nunca se alocou qualquer carga horária para essa atividade nem jamais se concedeu um bolsista para auxiliar em sua produção. 


\section{FACULDADE DE FORMAÇÃO DE PROFESSORES}

Houve até períodos em que se aconselhou os docentes do Departamento a não publicarem na SOLETRAS porque a publicação endógena teria menos valor acadêmico do que a publicação exógena.

Apesar de tudo, ela seguiu seu caminho e está prestes a tomar nova direção e se tornar uma referência nas publicações congêneres, porque outros docentes se engajaram no processo e há projeto de maior investimento de humor e trabalho na sua realização, com a Chefia do Departamento de Letras assumindo, efetivamente, a sua Direção, conforme consta ser desde que foi criada, em duas ou três reuniões do Departamento, a partir da sugestão da Profa. Iza Quelhas, de se criar uma publicação oficial do DEL.

A semente foi lançada e a árvore já cresceu e está produzindo frutos. É preciso cuidar dela para que continue produtiva e rentável por muito mais tempo ainda.

Rio de Janeiro, outubro de 2011.

Losé Peveina da Pilva 